Article

\title{
Use of Temperature and Humidity Sensors to Determine Moisture Content of Oolong Tea
}

Andrew Chen ${ }^{1}$, Hsuan-Yu Chen ${ }^{2}$ and Chiachung Chen ${ }^{3, *}$

1 Department of Electrical Engineering, National Taiwan University, Taipei 10617, Taiwan;

E-Mail: abcorchids@gmail.com

2 Department of Materials Science and Engineering, National ChungHsing University, Taichung 40227, Taiwan; E-Mail: bse@dragon.nchu.edu.tw

3 Department of Bio-industrial Mechatronics Engineering, National ChungHsing University, Taichung 40227, Taiwan

* Author to whom correspondence should be addressed; E-Mail: ccchen@dragon.nchu.edu.tw; Tel.: +886-4-2285-7562; Fax: +886-4-2285-7135.

Received: 22 June 2014; in revised form: 19 August 2014 / Accepted: 20 August 2014 /

Published: 22 August 2014

\begin{abstract}
The measurement of tea moisture content is important for processing and storing tea. The moisture content of tea affects the quality and durability of the product. Some electrical devices have been proposed to measure the moisture content of tea leaves but are not practical. Their performance is influenced by material density and packing. The official oven method is time-consuming. In this study, the moisture content of Oolong tea was measured by the equilibrium relative humidity technique. The equilibrium relative humidity, and temperature, of tea materials were measured by using temperature and relative humidity sensors. Sensors were calibrated, and calibration equations were established to improve accuracy. The moisture content was calculated by using an equilibrium moisture content model. The error of the moisture content determined with this method was within $0.5 \%$ w.b. at moisture $<15 \%$ w.b. Uncertainty analysis revealed that the performance of the humidity sensor had a significant effect on the accuracy of moisture determination.
\end{abstract}

Keywords: moisture measurement; tea leaves; equilibrium moisture content; equilibrium relative humidity; uncertainty analysis 


\section{Introduction}

Tea has become a popular beverage for people all over the world. Various types, and different manufacturing techniques, are found in different regions [1]. Oolong tea has a good reputation in Northern Asia. This tea is withered in the sun for fermentation to a moisture content of $50 \%$ to $60 \%$ w.b. Materials are then rolled into a round shape and dried to a final moisture content of $3 \%$ to $5 \%$ w.b. with high heat air of $110{ }^{\circ} \mathrm{C}$ to $120^{\circ} \mathrm{C}$. Oolong tea has become an expensive product in the tea market [2]. Tea moisture content is an important index. This moisture value influences the actual weight of tea products sold. The quality of the aroma and taste are influenced by moisture content. If the moisture content is maintained at a critical value, the quality can remain stable. Therefore, the tea industry requires an accurate, in situ and real-time, moisture meter [3].

The official method to measure tea moisture is the oven drying method. It requires a precise balance to detect the initial and final weights of samples, and the required time for all water in the sample to expire is $>24 \mathrm{~h}$ [1]. This method is inconvenient for in situ and real-time measurement.

Other techniques introduced include electrical impedance, microwave, infrared, and Neutron moderation [4]. The measurement of green tea moisture by microwave attenuation was described [5]). The ratio of the microwave attenuation to the sample weight (MASJ) was defined, and the relationship between MASJ and oven moisture content was established. The weight and density of samples significantly affected the measurement. The standard deviation of the moisture content was $6.8 \%$ w.b. The measurement of green tea moisture by electrical impedance and capacitance, simultaneously, was proposed by Mizukami et al. [3]. The ratio of impedance in ohm and capacitance was the independent variable. The calibration equation of the moisture content had a linear relationship with the independent variable and the standard error was 3.45\% w.b. Steaming treatment and maturity of the sample affected the performance. A fringe-field capacitor sensor with PC-based instrumentation was developed to detect the moisture content of tea leaves [6]. The depth of tea samples was controlled by shaking samples in a sensor cup. The moisture content was a function of the frequency shift of the empty probe and the probe with a sample. However, the performance of this instrumentation was not reported. To improve tea moisture measurement with the microwave transmission technique, a back-propagation (BP) algorithm was introduced [7]. Training artificial neural networks were adopted as the BP algorithm. The mean square error was reduced from 0.3805 to 0.0738 after the improvement. A new microstrip line-type moisture sensor for high-moisture tea leaves was reported [5]. The variables affecting moisture content included the ratio of the attenuation and phase shift of the microwave transmitted ion. The measurement error was nearly $3 \%$ with moisture from $155 \%$ to $215 \%$ on a dry basis (d.b.). The sample condition for these electrical techniques requires the uniform contact of sensing probes. The influencing factors included material density and known packing voids. As well, the electrical method was not suited for carbon materials. Thus, these techniques are not suitable for tea leaves.

At a fixed temperature, the moisture content of biological materials will reach an equilibrium state with the ambient relative humidity $(\mathrm{RH})$. The basic principle is an equilibrium state between the vapor pressure in the biological samples and ambient air [8]. A plot of equilibrium moisture content (EMC) and equilibrium relative humidity $(\mathrm{ERH})$, at constant temperature, is called the moisture sorption isotherm. Sorption equations describe the relationship between EMC, ERH, and temperature. 
Therefore, the moisture content of biological samples can be measured by the ERH and temperature at the equilibrium state, and then moisture content is calculated by an adequate sorption equation. The method was proposed by Young [9], and called the ERH technique [4]. The moisture content for two kinds of grain was determined by this method [10]. The ERH technique was adopted for measuring wood moisture. The moisture content was expressed as a complex equation with temperature and RH [11]. However, the results of practical testing were not mentioned.

Uddin et al. [12] evaluated the performance of accuracy, time response, and long-term stability for an RH/temperature sensor used to measure the moisture content of grains with this ERH technique. The EMC prediction error by an error propagation equation was studied. EMC prediction error at the high RH levels (>70\% w.b.) was increased substantially. Compared with RH error, a temperature error was found that had negligible effect on moisture content prediction.

This ERH technique was applied to measure seed moisture content by using a hygrometer [13]. To ensure measurement accuracy, the authors suggested that the hygrometer needed to be calibrated regularly. Karrfalt [14] introduced the ERH technique to measure seed moisture and emphasized the importance of the hygrometer calibration to maintain an accurate measurement. Besides being used to measure grains and seeds, the ERH technique was used to measure the moisture content of building materials [15].

Young [9] noted the limitations in the ERH technique: (1) the sample must be in an equilibrium state with the environment when the measurement is executed; (2) the accuracy is poor at high $\mathrm{RH}$, and (3) RH measurement has considerable error. Karrfalt [14] found that the benefits of the ERH technique for determining seed moisture included no limitation of species, the non-destructive method tested valuable seeds with no loss of material and results could be obtained in a few minutes.

The relationship between EMC, ERH, and temperature could be established by an ERH step-by-step method [16-19]. The evaluation of EMC/ERH models has been reported by many researchers $[1,2,20-23]$. The performance of the RH sensor could be improved by calibrating it with saturated salt solutions [24]. The improvement of the above technique provided the opportunity to apply the ERH technique to measure the moisture content of Oolong tea.

The first objective of this study was to develop an in situ, real-time method to determine tea moisture with the ERH technique. The second objective was to study the effect of the performance of $\mathrm{RH} /$ temperature sensors on determining moisture content with uncertainty analysis.

\section{Experimental Section}

\subsection{Definitions}

To avoid confusion, two terms were defined as follows:

\subsubsection{The Step-by-Step ERH Method}

The method is used to detect the ERH of a known moisture sample at fixed temperature. After measurement, the temperature is adjusted to the next level to wait for the equilibrium state and measure the next ERH value. 


\subsubsection{The ERH Technique}

A technique is used to measure the moisture content of the sample by the EMC equation. The ERH and temperature of the sample in an equilibrium state is measured. The moisture content of samples is calculated by its adequate EMC equation.

\subsection{Materials}

The tea used for this study was Chin-Shin Tung-Ting Oolong tea (Camellia sinensis (L.) Kuntze) grown and manufactured at the Lukung Township, Nantou, Taiwan. The initial moisture content of the sample was $2.91 \%$ on a w.b.

The desired moisture content ranged from $3 \%$ to $18 \%$ w.b., the moisture content for storing and processing. The samples were rewetted by adding an amount of the water to reach the desired moisture content. The sample preparation was according to the study of Shen and Chen [25]. Two independent tea samples with different moisture contents were prepared. The first was used to establish the EMC equation; the second was used to test the accuracy of the ERH technique. All samples were sealed in plastic containers and stored at $3{ }^{\circ} \mathrm{C}$ for three weeks to ensure uniform moisture content.

\subsection{Temperature and RH Sensors}

The temperature and RH probe of the Shinyei THT-B7T transmitter (Shinyei Kaisha Technology, Kobe, Japan) was used. The temperature probe was a Pt 100 sensing element and the humidity probe was the macro-molecule element. The specification of this transmitter is in Table 1.

Table 1. Specification of the Shinyei THT-B121 transmitter.

\begin{tabular}{ccc}
\hline & Temperature Sensor & RH Sensor \\
\hline Sensing element & RTD Pt $100 \mathrm{Ohm}$ & Macro-molecule HPR-MQ \\
Measuring range & 0 to $50{ }^{\circ} \mathrm{C}$ & $20 \%$ to $90 \% \mathrm{RH}$ \\
Accuracy before calibrating & $\pm 0.5^{\circ} \mathrm{C}$ & $\pm 3 \% \mathrm{RH}$ at $25^{\circ} \mathrm{C}$ \\
Precision & $0.1{ }^{\circ} \mathrm{C}$ & $1.0 \% \mathrm{RH}$ \\
Accuracy after calibrating & $\pm 0.15^{\circ} \mathrm{C}$ & $\pm 1.1 \% \mathrm{RH}$ \\
\hline
\end{tabular}

\subsection{Calibration of Sensors}

Five RH/temperature sensors were calibrated. The temperature probes were calibrated by using the TC-2000 temperature calibrator (Instutek AS, Skreppestad Naringspark, Norway) [26] and the humidity probe was calculated by several saturated salt solutions [24].

The inverse calibration technique was used. The standard value maintained by temperature calibrator and saturated salt solution was the independent variable $\left(y_{i}\right)$. The reading value of the $\mathrm{RH} /$ temperature sensor was the independent variable $\left(x_{i}\right)$. The coefficient of determination $\mathrm{R}^{2}$, standard error of the estimated values $\mathrm{s}$, and residual plots were used to evaluate the accuracy of the calibration equations of these sensors. 


\subsection{The Step-by-Step ERH Method}

The diagram of the experimental set-up in this study is in Figure 1.

Figure 1. The diagram of the experimental set-up.

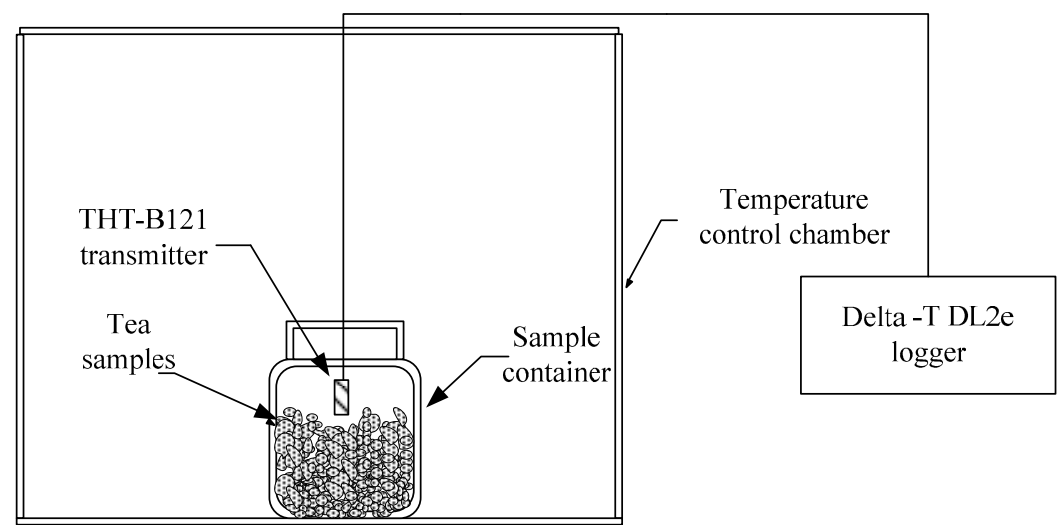

The moisture sorption isotherms of Oolong tea at nine temperatures (i.e., 5, 10, 15, 20, 25, 30, 35, 40, and $45{ }^{\circ} \mathrm{C}$ ) were measured by the step-by-step ERH method [16]. Samples of known moisture content were placed in 350-mL containers in a temperature control chamber. The RH/temperature sensing elements were inserted into containers. The head volume was near $50 \mathrm{~mL}$; the initial temperature of the temperature controller chamber was set to $5{ }^{\circ} \mathrm{C}$. When the $\mathrm{RH}$ and temperature within the sample containers reached the equilibrium state, $\mathrm{RH}$ and temperature were recorded. Then the temperature of the chamber was adjusted to the next level. All ERH values were measured at nine temperatures. The readings of RH and temperature of probes were calculated and transformed into actual values with calibration equations.

After finishing the measurement of sorption isotherms, samples were taken out from containers to determine the moisture content. The measurement of three replicates involved oven drying at $105{ }^{\circ} \mathrm{C}$ for $24 \mathrm{~h} \mathrm{[21].} \mathrm{The} \mathrm{moisture} \mathrm{content} \mathrm{was} \mathrm{expressed} \mathrm{on} \mathrm{a} \mathrm{d.b.}$

\subsection{The ERH Model}

The Oswin equation was used to express the relationship between EMC and ERH value at a fixed temperature [27]. This EMC equation was found adequate for tea $[1,2,21,28]$.

$$
M=A\left(\frac{E R H}{1-E R H}\right)^{B}
$$

where $\mathrm{M}$ is the moisture content in \%, $\mathrm{ERH}$ is the equilibrium relate humidity in decimal, and $\mathrm{A}$ and $\mathrm{B}$ are constants.

The relationship between the parameter $A$ and $B$ and temperature was further analyzed by regression analysis.

Regression analysis involved use of SigmaPlot v12.2 (SPSS Inc., Chicago, IL, USA). 


\subsection{Moisture Determination by the ERH Technique}

The same sensor, Shinyei THT-B121 transmitter, was used to evaluate the accuracy of the moisture determination by the ERH technique. Ten sample containers, $350 \mathrm{~mL}$, were filled with tea samples with different moisture levels. The sensing probe was placed in the middle position of the container, and then the cover was closed. The ERH and temperature were recorded by a data logger (Delta-T DL2e, Delta Devices Ltd., Cambridge, UK). The testing environment temperature was ranged from $15{ }^{\circ} \mathrm{C}$ to $35^{\circ} \mathrm{C}$. The $\mathrm{RH}$ and temperature values were transformed into actual values by use of a calibration equation. The measured moisture content of samples was calculated by the Oswin equation that was established in this study. The measured moisture contents were compared with that determined by the oven method. The measured time was $5 \mathrm{~min}$ for the lower moisture content $(<10 \% \mathrm{w} . \mathrm{b}$.) and $10 \mathrm{~min}$ for the higher moisture content (>10\% w.b.).

\subsection{Uncertainty Analysis}

The effect of the performance of RH and temperature sensors on measuring moisture content with the ERH technique was evaluated by uncertainty analysis. The concept of the combined standard uncertainty $U_{c}(y)$ was used [29]:

$$
u_{c}^{2}(y)=\sum_{i=1}^{n}\left(\frac{\partial f}{\partial x_{i}}\right)^{2} u^{2}\left(x_{i}\right)
$$

Because moisture content is a function of ERH and temperature, the combined standard uncertainty of the moisture content is expressed as follows:

$$
u_{c}^{2}(M)=\left(\frac{\partial M}{\partial E R H}\right)^{2} u^{2}(E R H)+\left(\frac{\partial M}{\partial T e m p}\right)^{2} u^{2}(T e m p)
$$

$u^{2}(E R H)$ and $u^{2}($ Temp $)$ are the uncertainty of ERH and temperature.

\subsection{Comparison Criterion}

\subsubsection{Quantitative Criteria}

Quantitative criteria were defined as follows:

$$
e_{i}=M_{c a l}-M_{\text {oven }}
$$

where $e_{\mathrm{i}}$ is the error of the ERH technique, $M_{c a l}$ is the moisture content determined by the ERH technique, and $M_{\text {oven }}$ is the moisture content determined by the oven method

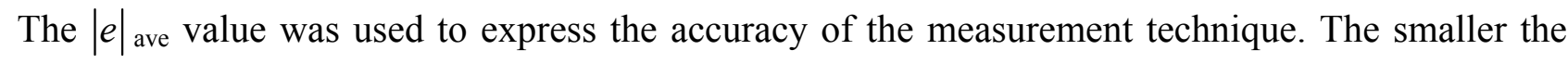
$|e|$ ave value, the better the accuracy.

$$
|e|_{\text {ave }}=\frac{\sum\left|e_{i}\right|}{n}
$$

where $\left|e_{i}\right|$ is the absolute $e_{i}$ value and $\mathrm{n}$ is the number of the data. 
The $e_{s t d}$ value was used to evaluate the precision of the measurement technique. The smaller the $e_{s t d}$ the better the precision.

$$
e_{s t d}=\left(\frac{e_{i}^{2}}{n-1}\right)^{0.5}
$$

\subsubsection{Qualitative Criteria}

The plot of error $e_{i}$ versus the standard value of the moisture content was a qualitative criterion to validate the ERH technique. If the ERH technique was accurate, these errors should be random. If the error distribution had a fixed pattern, then the ERH technique had fixed errors.

\section{Results and Discussion}

\subsection{Calibration Equation of RH/Temperature Sensors}

The calibration equations of five Shinyei THT-B121 transmitters are in Table 2. The calibration equations of temperature and $\mathrm{RH}$ were linear and three-order polynomial equations. Each sensor had a specific calibration equation.

Table 2. Calibration equation of five RH/Temperature sensors.

\begin{tabular}{ccc}
\hline $\begin{array}{c}\text { No. of } \\
\text { Sensors }\end{array}$ & Temperature Sensor & RH Sensor \\
\hline 1 & $y_{t 1}=1.0066 \times x_{t 1}-0.1256$ & $y_{r 1}=7.3338 \times 10^{-5} x_{r 1}^{3}-1.3827 \times 10^{-2} x_{r 1}^{2}+1.7738 x_{r 1}-10.9066$ \\
2 & $y_{t 2}=1.0021 \times x_{t 2}-0.0584$ & $y_{r 2}=5.9093 \times 10^{-5} x_{r 2}^{3}-1.1491 \times 10^{-2} x_{r 2}^{2}+1.6649 x_{r 2}-9.8379$ \\
3 & $y_{t 3}=1.0092 \times x_{t 3}-0.0197$ & $y_{r 3}=5.8050 \times 10^{-5} x_{r 3}^{3}-1.1678 \times 10^{-2} x_{r 3}^{2}+1.6688 x_{r 3}-9.0222$ \\
4 & $y_{t 4}=1.0099 \times x_{t 4}-0.0581$ & $y_{r 4}=6.5228 \times 10^{-5} x_{r 4}^{3}-1.2356 \times 10^{-2} x_{r 4}^{2}+1.6799 x_{r 4}-8.9418$ \\
5 & $y_{t 5}=1.0047 \times x_{t 5}-0.0492$ & $y_{r 5}=7.3492 \times 10^{-5} x_{r 5}^{3}-1.4079 \times 10^{-2} x_{r 5}^{2}+1.7851 x_{r 5}-10.3870$ \\
\hline
\end{tabular}

\subsection{Sorption Isotherms of Oolong Tea}

The sorption data at five temperatures are shown in Figure 2. Temperature significantly affected the sorption isotherm. The effect of temperature on EMC was consistent with results with Central African tea [23], black and green tea [1], black tea [22], and fresh tea [28].

The results of the estimated parameters and comparison statistics for the Oswin equation at different temperatures are in Table 3. The effect of temperature on the parameters A and B is in Figure 3.

The empirical regression equations between parameters and temperature were established. The equation for $\mathrm{A}$ was expressed as:

$$
\mathrm{A}=6.9229-0.0284 \mathrm{Temp}+5.3964 \times 10^{-4} \mathrm{Temp}^{2}, R^{2}=0.9784, s=0.0165
$$

Because the range of A was 6.5390 to 6.7870 , A may be treated as its average value to simply the Oswin equation. That is, if the effect of temperature on A with temperature was neglected, A could be considered a constant and expressed by its average value.

$$
\mathrm{A}=6.6433 \text { (temperature range } 5-45^{\circ} \mathrm{C} \text { ) }
$$


Figure 2. Sorption data for Oolong tea at five temperatures.

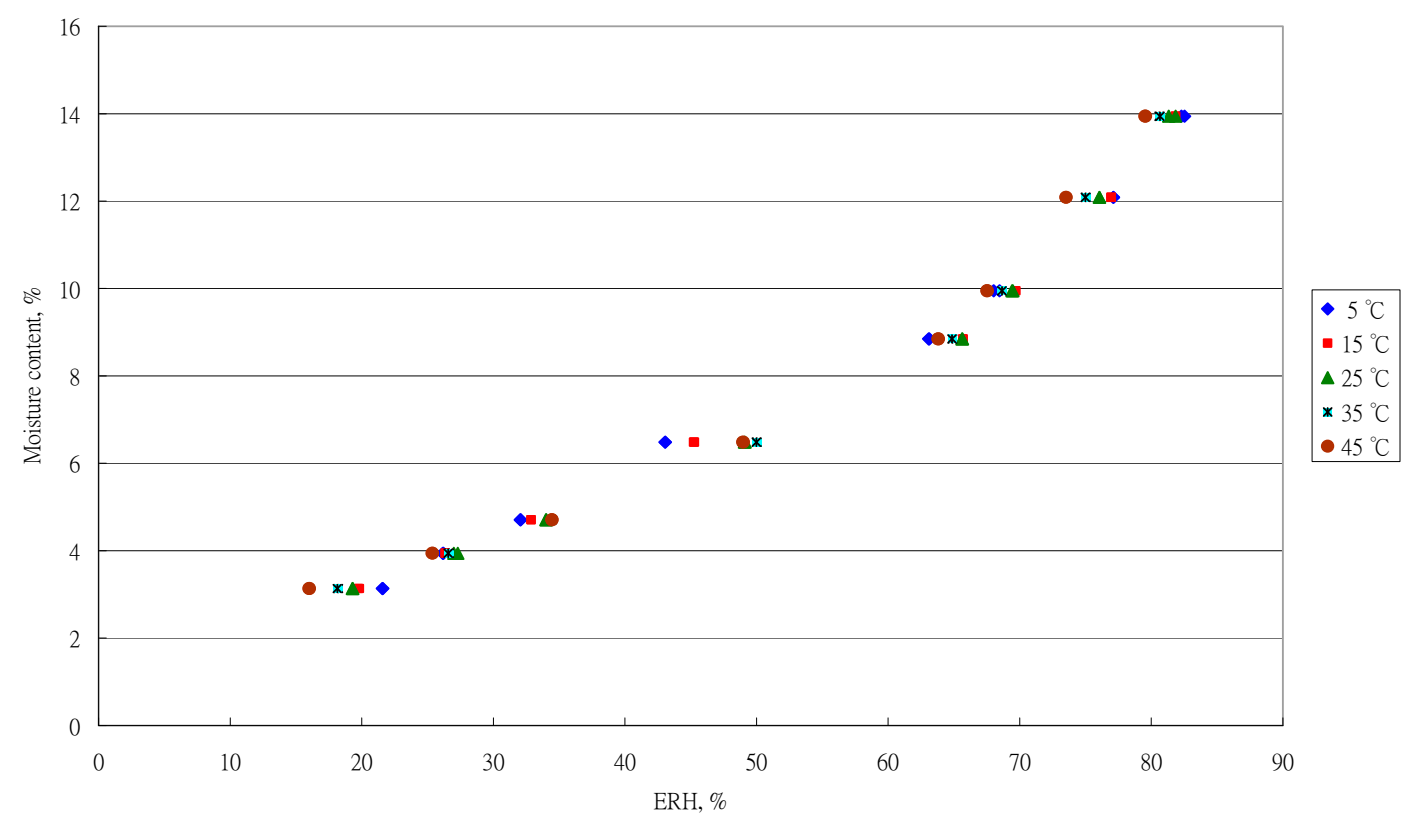

Table 3. Estimated values of parameters in the Oswin equation.

\begin{tabular}{ccccc}
\hline Temperature & \multicolumn{2}{c}{ Parameters } & $\begin{array}{c}\text { Coefficients of } \\
\text { Determination }\end{array}$ & $\begin{array}{c}\text { Standard of Deviations } \\
\text { of Estimated Values }\end{array}$ \\
\hline${ }^{\circ} \mathbf{C}$ & $\mathbf{A}$ & $\mathbf{B}$ & $R^{2}$ & $\mathbf{s}$ \\
\hline 5 & 6.7815 & 0.4758 & 0.9935 & 0.3195 \\
10 & 6.7095 & 0.4870 & 0.9950 & 0.2611 \\
15 & 6.6364 & 0.4919 & 0.9971 & 0.2165 \\
20 & 6.5472 & 0.5065 & 0.9971 & 0.1710 \\
25 & 6.5390 & 0.5124 & 0.9985 & 0.1536 \\
30 & 6.5468 & 0.5240 & 0.9985 & 0.1559 \\
35 & 6.5970 & 0.5276 & 0.9981 & 0.1748 \\
40 & 6.6456 & 0.5331 & 0.9973 & 0.2064 \\
45 & 6.7870 & 0.5321 & 0.9960 & 0.2494 \\
\hline
\end{tabular}

In the practical application for tea processing and storage, the ambient temperature was $<40{ }^{\circ} \mathrm{C}$. The A value was expressed as:

$$
\left.\mathrm{A}=6.6254 \text { (temperature range } 5-40{ }^{\circ} \mathrm{C}\right)
$$

The empirical equation for B was expressed as:

$$
\mathrm{B}=0.4718+1.5031 \times 10^{-3} \mathrm{Temp}\left(\text { range } 5-45^{\circ} \mathrm{C}\right), R^{2}=0.9311, \mathrm{~s}=0.0163
$$

or,

$$
\mathrm{B}=0.4674+1.7687 \times 10^{-3} \mathrm{Temp}\left(\text { range } 5-40{ }^{\circ} \mathrm{C}\right), R^{2}=0.9789, \mathrm{~s}=0.0067
$$

Comparing the $\mathrm{R}^{2}$ and s values, Equation (11) had better fitting ability than Equation (10). 
Figure 3. Effect of temperature on parameters $\mathrm{A}$ and $\mathrm{B}$ of the Oswin equation. (A) Parameter A; (B) Parameter B.

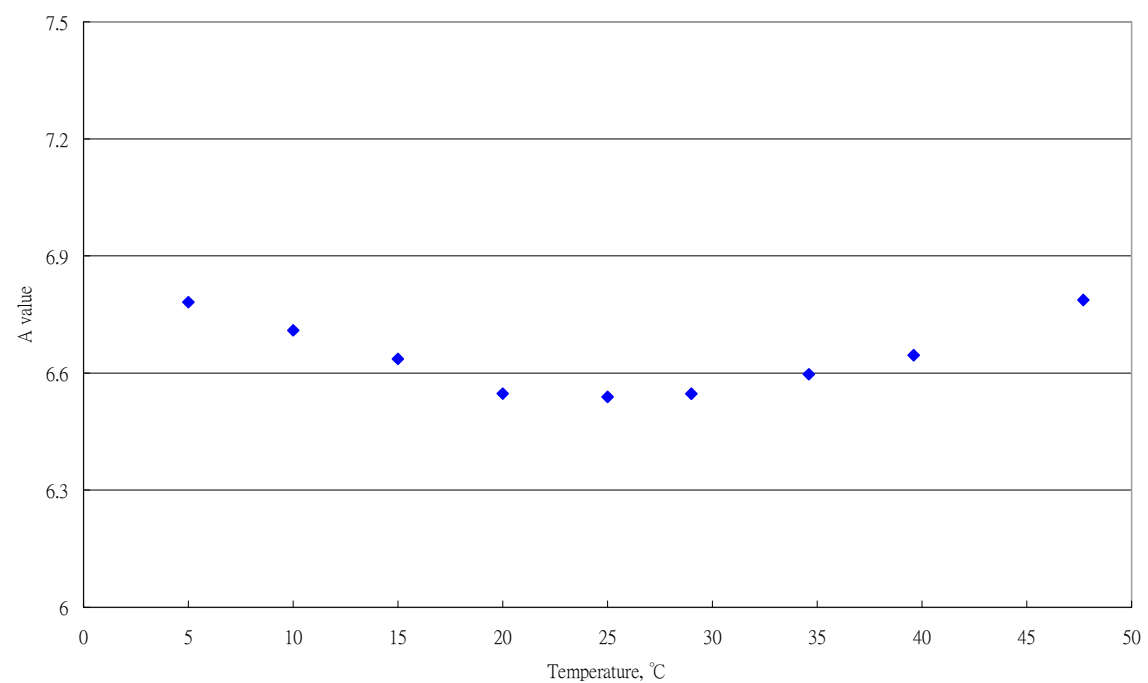

(A)

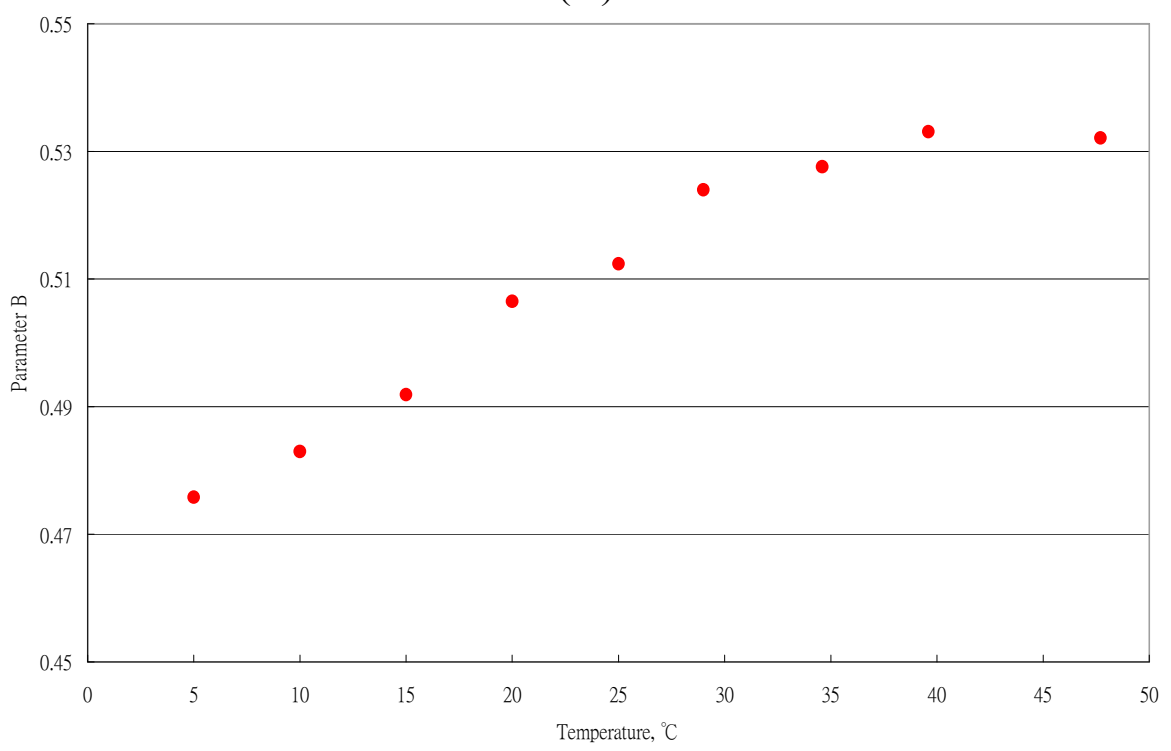

(B)

\subsection{Moisture Determination with the ERH Technique}

The typical measurement of ERH in samples with different moisture content at $25{ }^{\circ} \mathrm{C}$ is in Figure 4 . The ERH values at 10 min were transformed into actual values by its calibration equation.

Three forms of the Oswin equation that incorporated the temperature term were proposed as follows:

$$
\begin{gathered}
M_{p 1}=\left(6.9229-0.0284 \text { Temp }+5.3764 \times 10^{-4} \text { Temp }^{2}\right)\left(\frac{E R H}{1-E R H}\right)^{\left(0.4718+1.5031 \times 10^{-3} \text { Temp }\right)} \\
M_{p 2}=6.6433\left(\frac{E R H}{1-E R H}\right)^{\left(0.4718+1.5031 \times 10^{-3} \mathrm{Temp}\right)} \\
M_{p 3}=6.6254\left(\frac{E R H}{1-E R H}\right)^{\left(0.4674+1.7687 \times 10^{-3} \mathrm{Temp}\right)}
\end{gathered}
$$


The moisture content calculated by Equations (12)-(14) was compared with the standard values. The results are in Figure 5. Moisture measurements showed a uniform distribution along the $\mathrm{X}=\mathrm{Y}$ line. No over- or underestimating data pattern could be found. The results validated the ERH technique.

Figure 4. Equilibrium relative humidity $(\mathrm{ERH})$ values of samples with five low moisture contents at $25^{\circ} \mathrm{C}$. (A) Low moisture contents; (B) High moisture contents.

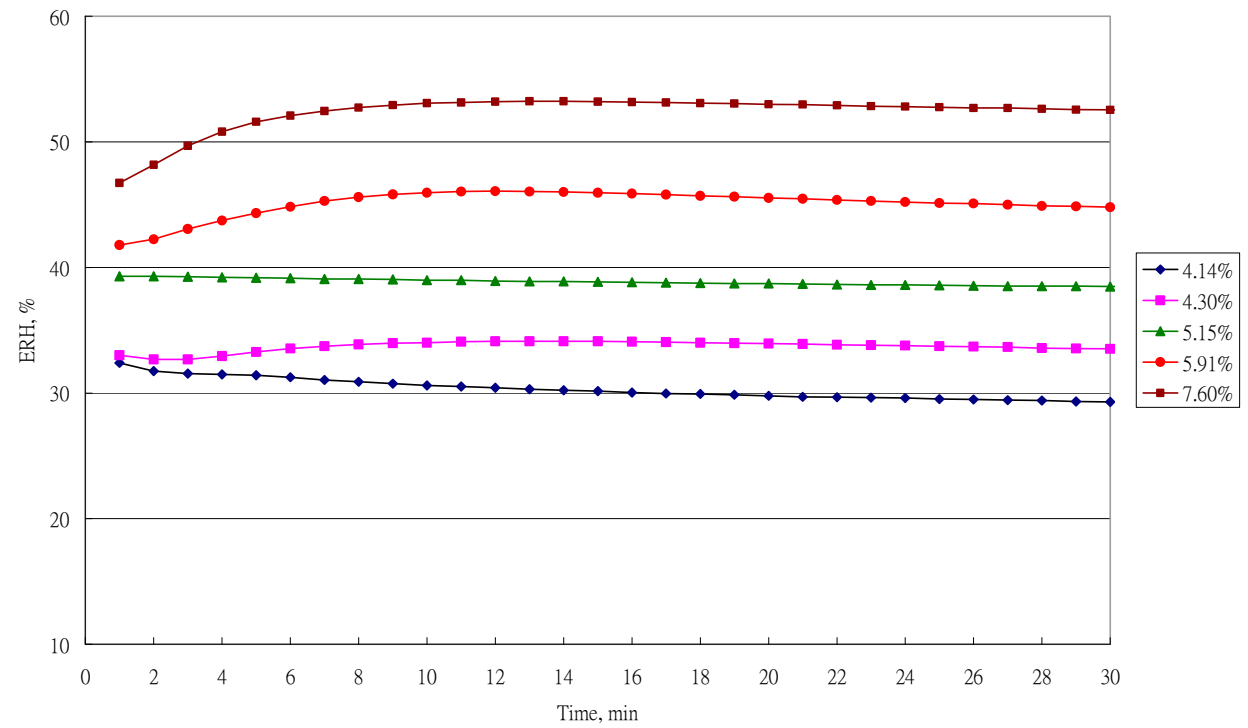

(A)

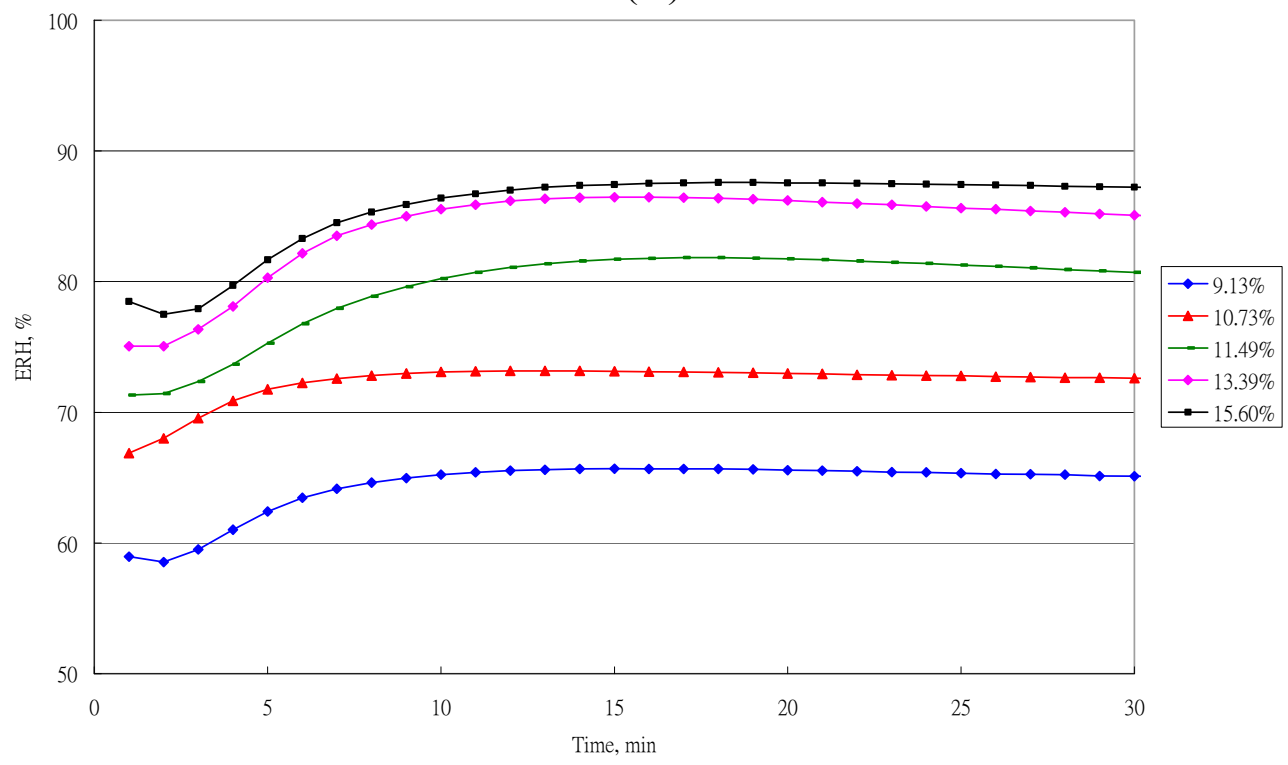

(B)

The error distribution of the moisture measurement calculated by the three $M_{p i}$ equations is in Figure 6. At low moisture range $\left(<10 \%\right.$ w.b.), the error distribution for $M_{p 1}$ and $M_{p 3}$ range from $-0.5 \%$ to $0.5 \%$ w.b. At a high moisture ( $>10 \%$ w.b.), the error distribution for the three $M_{p i}$ values ranged from $-1 \%$ to $1 \%$ w.b. The corresponding ERH value for a moisture content of $10 \%$ was $70 \%$ RH. That is, the ERH technique had a better performance at $\mathrm{RH}<70 \%$. These findings for RH range by ERH technique were similar to those the results of Uddin et al. [12]. The work environment for the 
tea processing, packing and storing was within this range $[1,2,22,23]$. From a practical perspective, moisture content could be determined by the ERH technique. The high errors at high RH range may be due to the fact that the equilibrium time was not enough for tea materials.

Figure 5. Comparison of the moisture contents using the ERH technique and standard values using the oven method.

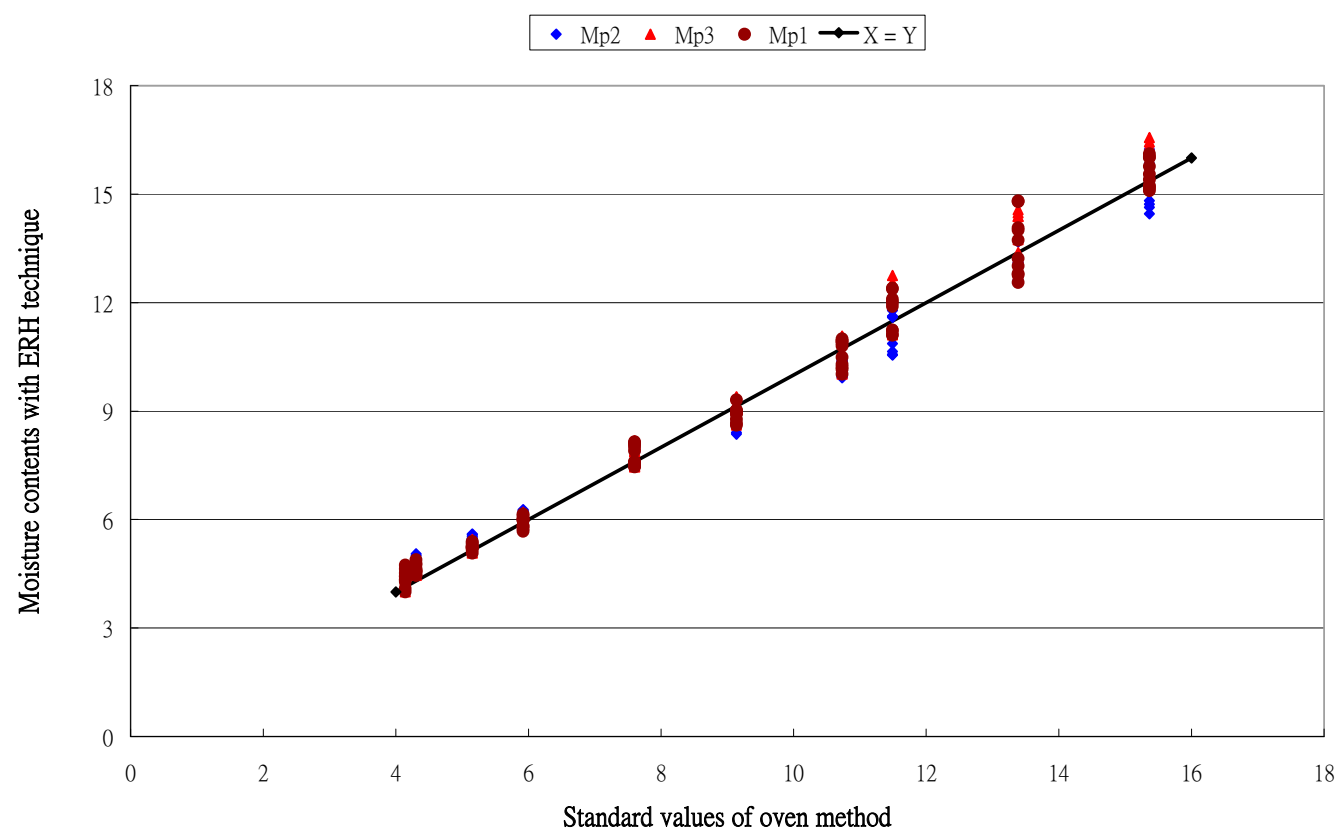

Figure 6. Error distribution of moisture measurements, calculated by three $M_{p i}$ equations. (A) the $\mathrm{M}_{\mathrm{p} 1}$ equation; (B) the $\mathrm{M}_{\mathrm{p} 2}$ equation; (C) the $\mathrm{M}_{\mathrm{p} 3}$ equation.

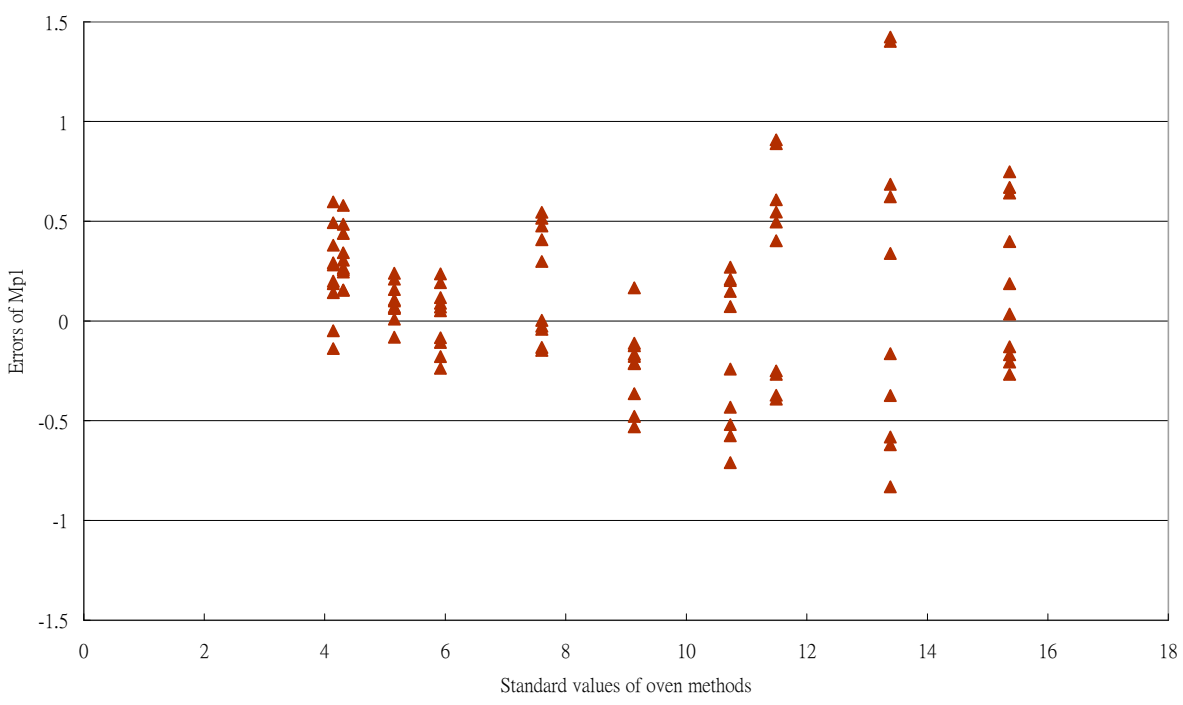

(A) 
Figure 6. Cont.

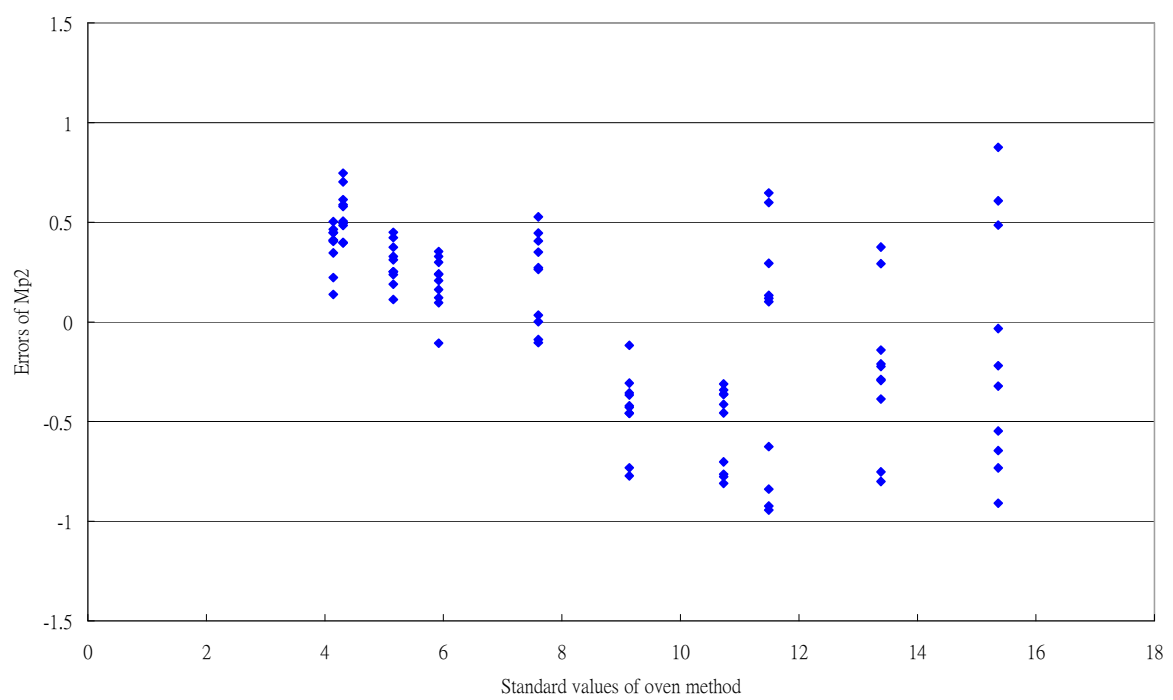

(B)

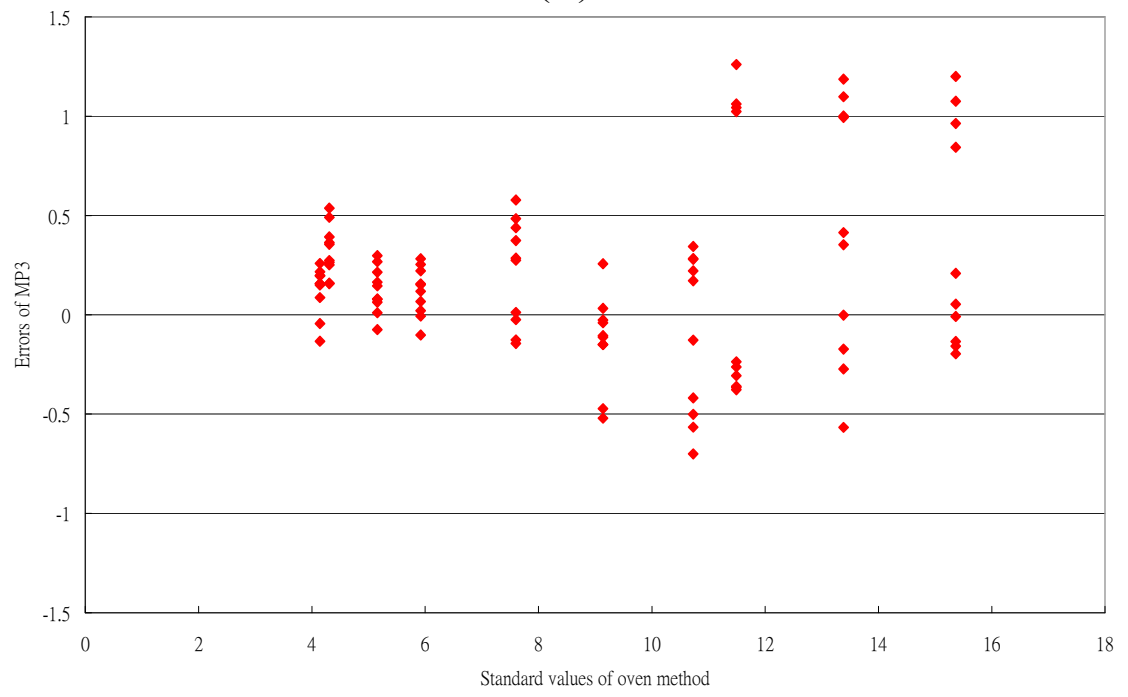

(C)

The quantitative criteria for the three $M_{p i}$ equations are in Table 4.

Table 4. Criteria for comparing of three forms of the Oswin equation.

\begin{tabular}{cccc}
\hline & $M_{p 1}$ & $M_{p 2}$ & $M_{p 3}$ \\
\hline$e_{\min }$ & -0.8305 & -0.9438 & -0.7006 \\
$e_{\max }$ & 1.4236 & 1.1768 & 1.2606 \\
$|e|_{\text {ave }}$ & 0.3260 & 0.4097 & 0.3304 \\
$e_{\text {std }}$ & 0.4309 & 0.4796 & 0.4455 \\
\hline
\end{tabular}

The $M_{p 1}$ equation incorporating temperature into both parameters had the smallest values of $e_{s t d}$ and the $M_{p 2}$ equation had the largest $e_{\min },|e|_{\text {ave }}$ and $e_{s t d}$ values. The $|e|_{\text {ave }}$ and $e_{s t d}$ values of the $M_{p 3}$ equation were closed to those of the $M_{p 1}$ equation. $M_{p 1}$ and $M_{p 3}$ equations could be adequate equations. The form of the $M_{p 3}$ equation was simpler. This equation was used for the uncertainty analysis. 
The moisture content of stored tea products is usually checked by the oven method, which is laborious and time consuming. With the ERH technique, samples were placed in a container and an $\mathrm{RH} /$ temperature sensor was inserted into samples to measure the ERH and temperature after a short period. Then the moisture content could be calculated easily with the established ERH equation. The ERH technique should provide a reliable, rapid, and inexpensive method to determine the moisture content of tea products. The package voids and materials density limits the ability to detect moisture content with electrical devices. This ERH technique could be used for other products, such as medical herbs or agricultural products.

\subsection{Uncertainty Analysis of Moisture Content}

Parameter B of the Oswin equation was incorporated into the temperature term as follows:

$$
M=A\left(\frac{E R H}{1-E R H}\right)^{\left(b_{0}+b_{1} \text { Temp }\right)}
$$

To calculate the combined uncertainty of the moisture determination technique, the partial derivatives of $\mathrm{M}$ with ERH and temperature were as follows:

$$
\begin{gathered}
\frac{\partial M}{\partial(E R H)}=A\left(b_{0}+b_{1} \text { Temp }\right)\left(\frac{E R H}{1-E R H}\right)^{\left(b_{0}+b_{1} \text { Temp }-1\right)}\left(\frac{1}{1-E R H}\right)^{2} \\
\frac{\partial M}{\partial T e m p}=A\left(\frac{E R H}{1-E R H}\right)^{\left(b_{0}+b_{1} \text { Temp }\right)} \operatorname{Ln}\left(\frac{E R H}{1-E R H}\right)\left(b_{1}\right)
\end{gathered}
$$

Equations (16) and (17) were substitute into Equation (3). The uncertainty of the RH sensor, $\mathrm{u}(\mathrm{ERH})$ was $3 \%$ before calibration and $1.1 \%$ after calibration [24]. The uncertainty of the temperature sensor, $\mathrm{u}(\mathrm{Temp})$ was $0.5{ }^{\circ} \mathrm{C}$ before calibration and $0.15{ }^{\circ} \mathrm{C}$ after calibration [26]. The uncertainty sources of replications of the measurement and the equilibrium state of the humidity were not considered.

The calculation results of the uncertainty for moisture content by the ERH technique at seven RH levels and three temperatures are in Table 5. The significant effects of the uncertainty were due to the performance of the RH sensors. The temperature sensor had margin effect.

The effect of the sensor performance on the moisture uncertainty is in Figure 7. At a high RH, the effect of sensor performance was more obvious. To obtain an accuracy measurement of the moisture content by using the ERH technique, the RH sensor needs to be calibrated. The calibration equations need to be established individually.

The effect of the temperature environment on moisture determination is in Figure 8. The temperature effect could be neglected. The result was the same as for Uddin et al. [12]. Recently, the performance of temperature sensors has been improved in the instrumentation industry. The key technique for determining tea moisture is the performance of RH sensors.

The actual errors of the ERH technique in Figure 6 were larger than in the uncertainty analysis. The reason could be explained by the fact that other uncertainty sources, such as errors of the standard method, repeatability of sampling and the effect of the equilibrium state, were not considered in this uncertainty analysis. 
Table 5. The calculation results of the uncertainty for moisture content by ERH technique at seven RH levels and three temperatures.

\begin{tabular}{cccccccc}
\hline ERH & Temp & $\mathbf{u}(\mathbf{E R H})=$ & $\mathbf{u}(\mathbf{E R H})=$ & $\mathbf{u}(\mathbf{T e m p})=$ & $\mathbf{u}($ Temp$)=$ & $\mathbf{u}(\mathbf{m})$ & $\mathbf{u}(\mathbf{m})$ \\
\hline & & $\mathbf{0 . 0 3}$ & $\mathbf{0 . 0 1 1}$ & $\mathbf{0 . 5}{ }^{\circ} \mathbf{C}$ & $\mathbf{0 . 1 5}{ }^{\circ} \mathbf{C}$ & No Calibration & Calibration \\
\hline 0.2 & 15 & 0.3019 & 0.1107 & $8.25 \mathrm{E}-06$ & $2.47 \mathrm{E}-06$ & 0.3019 & 0.1107 \\
0.3 & 15 & 0.3030 & 0.1111 & $9.05 \mathrm{E}-06$ & $2.72 \mathrm{E}-06$ & 0.3030 & 0.1111 \\
0.4 & 15 & 0.3324 & 0.1219 & $5.02 \mathrm{E}-06$ & $1.50 \mathrm{E}-06$ & 0.3324 & 0.1219 \\
0.5 & 15 & 0.3927 & 0.1440 & 0 & 0 & 0.3927 & 0.1440 \\
0.6 & 15 & 0.5033 & 0.1846 & $2.54 \mathrm{E}-05$ & $7.62 \mathrm{E}-06$ & 0.5033 & 0.1846 \\
0.7 & 15 & 0.7211 & 0.2644 & 0.000268 & $8.05 \mathrm{E}-05$ & 0.7211 & 0.2644 \\
0.8 & 15 & 1.2470 & 0.4572 & 0.002111 & 0.000633 & 1.2470 & 0.4572 \\
0.2 & 25 & 0.3051 & 0.1119 & $8.25 \mathrm{E}-06$ & $2.47 \mathrm{E}-06$ & 0.3051 & 0.1119 \\
0.3 & 25 & 0.3092 & 0.1134 & $9.05 \mathrm{E}-06$ & $2.72 \mathrm{E}-06$ & 0.3092 & 0.1134 \\
0.4 & 25 & 0.3419 & 0.1253 & $5.02 \mathrm{E}-06$ & $1.50 \mathrm{E}-06$ & 0.3419 & 0.1253 \\
0.5 & 25 & 0.4068 & 0.1491 & 0 & 0 & 0.4068 & 0.1491 \\
0.6 & 25 & 0.5251 & 0.1925 & $2.54 \mathrm{E}-05$ & $7.62 \mathrm{E}-06$ & 0.5251 & 0.1925 \\
0.7 & 25 & 0.7582 & 0.2780 & 0.000268 & $8.05 \mathrm{E}-05$ & 0.7582 & 0.2780 \\
0.8 & 25 & 1.3238 & 0.4854 & 0.002111 & 0.000633 & 1.3238 & 0.4854 \\
0.2 & 35 & 0.3317 & 0.1216 & $8.25 \mathrm{E}-06$ & $2.47 \mathrm{E}-06$ & 0.3317 & 0.1216 \\
0.3 & 35 & 0.3297 & 0.1209 & $9.05 \mathrm{E}-06$ & $2.72 \mathrm{E}-06$ & 0.3297 & 0.1209 \\
0.4 & 35 & 0.3588 & 0.1316 & $5.02 \mathrm{E}-06$ & $1.50 \mathrm{E}-06$ & 0.3588 & 0.1316 \\
0.5 & 35 & 0.4208 & 0.1543 & 0 & 0 & 0.4208 & 0.1543 \\
0.6 & 35 & 0.5355 & 0.1963 & $2.54 \mathrm{E}-05$ & $7.62 \mathrm{E}-06$ & 0.5355 & 0.1963 \\
0.7 & 35 & 0.7611 & 0.2791 & 0.000268 & $8.05 \mathrm{E}-05$ & 0.7611 & 0.2791 \\
0.8 & 35 & 1.3034 & 0.4779 & 0.002111 & 0.000633 & 1.3034 & 0.4779 \\
\hline
\end{tabular}

u: uncertainty.

Figure 7. Effect of the sensor performance on the moisture uncertainty calculation.

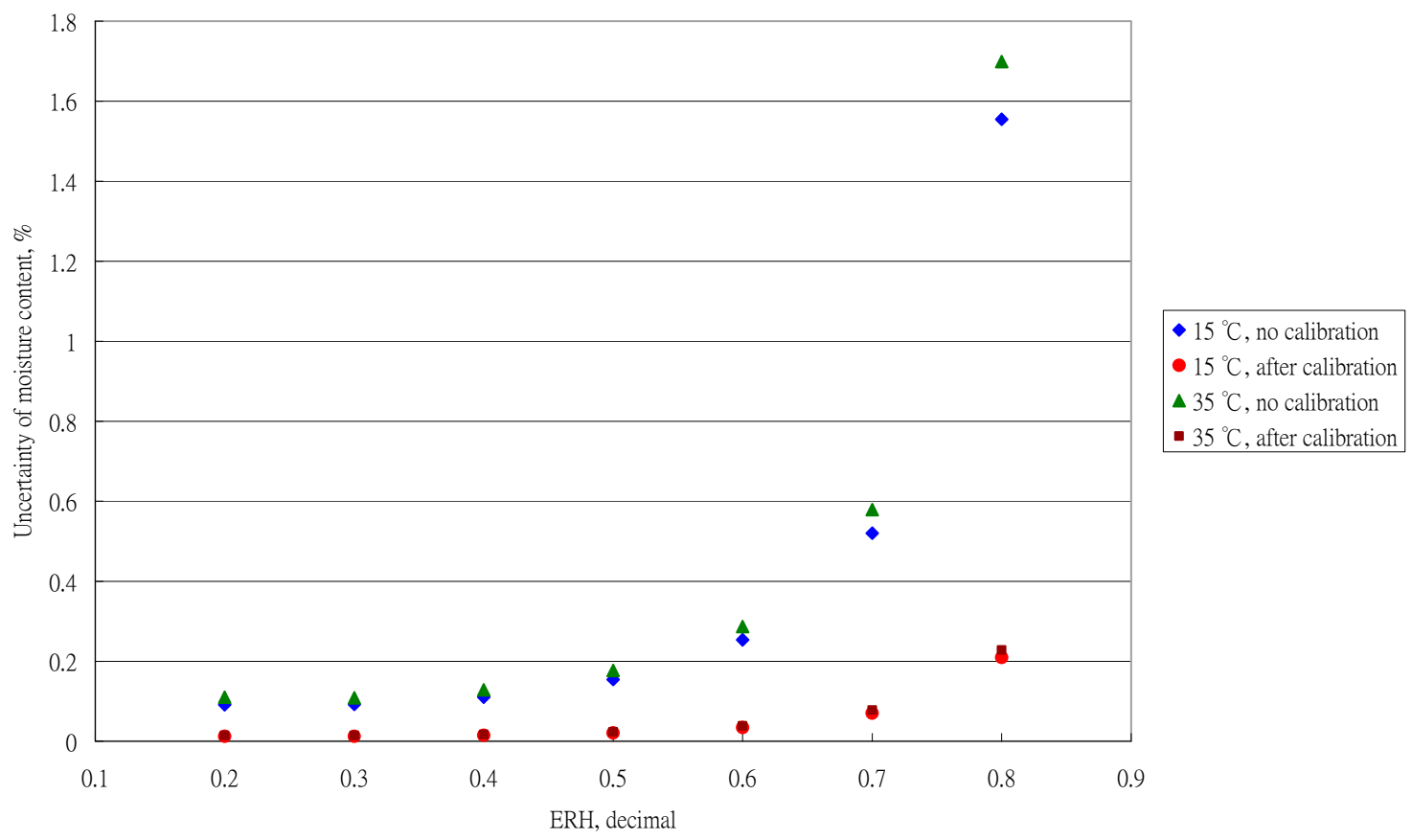


Figure 8. Effect of the temperature environment on moisture determination.

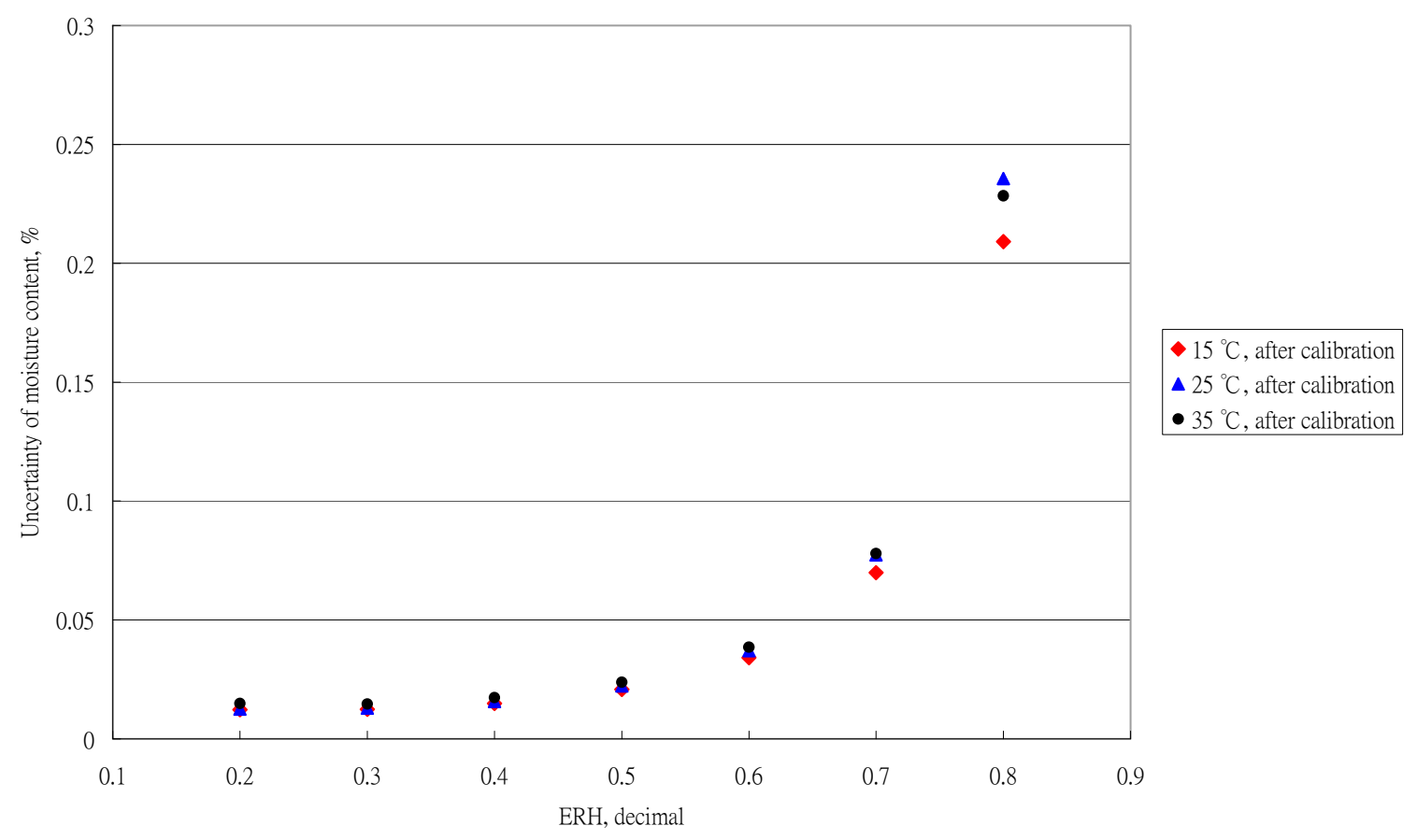

\section{Conclusions}

The EMC and ERH data for Oolong tea at nine temperatures were determined with a step-by-step ERH method with the first sample. The parameters of the Oswin equation were estimated with regression analysis and the temperature term was incorporated into the parameter. With a second sample, different moisture contents were used to evaluate the ERH technique of moisture determination. The accuracy of the moisture determination was within $0.5 \%$ w.b. by the ERH technique at $\mathrm{RH}<70 \%$. The moisture was $<15 \%$ w.b. Moisture content determined with the ERH technique has practical applications. This ERH technique could be used for other products, such as medical herbs or other agricultural products. The uncertainty analysis revealed that the performance of the humidity sensor had a significant effect on the accuracy of moisture determination.

\section{Acknowledgments}

The authors would like to thank the National Science Council of the Republic of China for financially supporting this research under Contract No. 98-2313-B-005-032-MY3.

\section{Author Contributions}

Andrew Chen modified the equipment and performed the experiments, compared the results and involved in all implementation stages of the project drafted the manuscript. Hsuan-Yu Chen reviewed the proposal, executed the statistical analysis, interpreted the results and revised the manuscript. Chiachung Chen drafted the proposal, performed some experiments, interpreted some results and read the manuscript critically and participated in its revision. All authors have read and approved the final manuscript. 


\section{Conflicts of Interest}

The authors declare no conflict of interest.

\section{References}

1. Ghodake, H.M.; Goswami, T.K.; Chakraverty, A. Moisture sorption isotherms, heat of sorption and vaporization of withered leaves, black and green tea. J. Food Eng. 2007, 78, 827-835.

2. Chen, C.; Weng, Y. Moisture sorption isotherms of Oolang tea. Food Bioproc. Technol. 2010, 3, 226-233.

3. Mizukami, Y.; Sawai, Y.; Yamaguchi, Y. Moisture content measurement of tea leaves by electrical impedance and capacitance. Biosyst. Eng. 2006, 93, 293-299.

4. Meadocroft, D.B. Chemical analysis: Moisture Measurement. In Instrumentation Reference Book; Butterworth-Heinemann/Elsevier: Burlington, MA, USA, 2010; pp. 429-436.

5. Okamura, S.; Zhang, Y.; Tsukamoto, N. A new microstripline-type moisture sensor for heavily wet tea leaves. Meas. Sci. Technol. 2007, 18, 1022-1028.

6. Hazarika, D.; Laskar, S.; Sarma, A.; Sarmah, P.K. PC-Based instrumentation system for the detection of moisture content of tea leaves at its final stage. IEEE T. Instrum. Meas. 2006, 55, 1641-1647.

7. Jiang, Y.; Guo, L.; Yang, G. Developed BP algorithm in moisture content measurement. In Proceedings of 2006 IEEE International Conference on Industrial Informatics, Singapore, 16-18 August 2006.

8. Chen, C. Factors which effect equilibrium relative humidity of agricultural products. Trans. ASAE 2000, 43, 673-683.

9. Young, J.H. Moisture. In Instrumentation and Measurement for Environmental Sciences; Chapter 7; ASABE: St. Joseph, MI, USA, 1983.

10. Chen, C. Moisture measurement of grain using humidity sensors. Trans. ASAE 2001, 44, 1241-1245.

11. Tangirala, P.; Heath, J.R.; Radun, A.; Conners, T. A hand-held programmable-Logic-Device based temperature and relative-humidity sensor, processor and display system platform for automation and control of industry processes. IEEE Trans. Ind. Appl. 2008, 46, 1619-1629.

12. Uddin, M.S.; Armstrong, P.R.; Zhang, N. Accuracy of grain moisture content prediction using temperature and relative humidity sensors. Appl. Eng. Agric. 2006, 22, 267-273.

13. Gold, K.; Manger, K. Measuring Seed Moisture Status Using a Hygrometer. Technical Information Sheet 05; Board of Trustees of the Royal Botanic Gardens: Kew West Sussex, UK, 2008

14. Karrfalt, R.P. Equilibrium relative humidity as a tool to monitor seed moisture. In Proceedings of the Forest and Conservation Nursery Associations-2009, Fort Collins, CO, USA, July 2009.

15. Wernecke, R.; Wernecke, J. Moisture Measurement in the Building Industry. In Industrial Moisture and Humidity Measurement: A Practical Guide, 1st ed.; Wiley-VCH Verlag GmbH \& Co. HGaA: Weinheim, Germany, 2014; pp. 361-384.

16. Chen, C.; Morey, R.V. Equilibrium relativity humidity (ERH) relationships for yellow-dent corn. Trans. ASAE 1989, 32, 999-1006. 
17. Chen, C. A rapid method to determine the sorption isotherms of peanuts. J. Agr. Eng. Res. 2000b, $75,401-408$.

18. Chen, C. Sorption isotherms of sweet potato slices. Biosyst. Eng. 2002a, 83, 85-95.

19. Chen. C. Moisture sorption isotherms of pea seeds. J. Food Eng. 2002b, 58, 45-51.

20. ASABE, ASABE Standards. ASAE D245.6.15 DEC02: Moisture Relationships of Plant-Based Agricultural Products; ASABE: St. Joseph, MI, USA, 2007.

21. Arslan, N.; Togrul, H. The fitting of various models to water sorption isotherms of tea stored in a chamber under controlled temperature and humidity. J. Stored Prod. Res. 2006, 42, 112-135.

22. Panchariya, P.C.; Popovic, D.; Sharma, A.L. Modeling of desorption isotherm of black tea. Dry. Technol. 2001, 19, 1177-1188.

23. Temple, S.J.; van Boxtel, A.J.B. Equilibrium moisture content of tea. J. Agr. Eng. Res. 1999, 74, 83-89.

24. Lu, H.; Chen, C. Uncertainty evaluation of humidity sensors calibrated by saturated salt solutions. Measurement 2007, 40, 591-599.

25. Shen, Y.; Chen, C. Preparation of reference materials for rice kernels. Biosyst. Eng. 2007, 97, 41-49.

26. Chen, C. Evaluation of measurement uncertainty for thermometers with calibration equations. Accredit. Qual. Assur. 2005, 11, 75-82.

27. Oswin, C. The kinetics of package life. III. The isotherm. J. Soc. Chem. Ind. 1946, 65, 419-421.

28. Botheju, S.W.; Amaratunge, K.S.P.; Abeysinghe, I.S.B. Modeling desorption isotherms and thermodynamic properties of fresh tea leaves (Camellia sinensis var. assamica). Int. J. of Food Eng. 2012, 8, 1-16.

29. ISO/IEC., ISO/IEC 98-3. Uncertainty of Measurement-Part 3: Guide to the Expression of Uncertainty in Measurement, ISO ed.; ISO/IEC: Geneva, Switzerland, 2010.

(C) 2014 by the authors; licensee MDPI, Basel, Switzerland. This article is an open access article distributed under the terms and conditions of the Creative Commons Attribution license (http://creativecommons.org/licenses/by/3.0/). 